\title{
Sildenafil (Viagra) as a Possible Culprit for Vision Loss
}

\section{Maryam Naser MD* and Nafiseh Hashemi MD}

Neuro-ophthalmology Clinic, Hashemi Eye Care, USA

*Corresponding author: Maryam Naser, Neuro-ophthalmology Clinic, Hashemi Eye Care, Encino, California, USA.
Received Date: August 05, 2019

Published Date: August 09, 2019

\section{Abstract}

Non-Arteritic Anterior Ischemic Optic Neuropathy (NAION) is the most common clinical presentation of acute ischemic damage to the optic nerve. In this case report, we are presenting a patient with bilateral sequential NAION who had a history of blood clothing disorders and found to have NAION in the second eye immediately after use of Sildenafil for erectile dysfunction.

\section{Introduction}

The patient is a 57-year-old male who had optic nerve atrophy following NAION in left eye on December 2017. Vision loss in the left eye had happened one month after his second pulmonary emboli while he was on Rivaroxaban (Xarelto). His extensive coagulopathy work up has been inconclusive. He developed vision loss in the right eye few months after. He was diagnosed with ischemic optic neuropathy and referred to neuro-ophthalmology clinic. He denied headaches, scalp tenderness, jaw pain, fever and weight loss. Review of systems was negative. His past medical history includes primary hypertension and pulmonary embolism. His brother had history of deep vein thrombosis (DVT). He was taking Amlodipine and rivaroxaban (Xarelto).

In eye examination, visual acuity right eye is $20 / 40$ and left eye $8 / 200$. Color vision is $1 / 11$ and $0 / 11$. The patient has RAPD in left eye. Visual fields show generalized constriction in both eyes. Fundus photo and OCT optic nerve indicating RNFL thinning (RNF thickness OD:53 micron and OS:42 micron) are shown below (Figure 1-3).
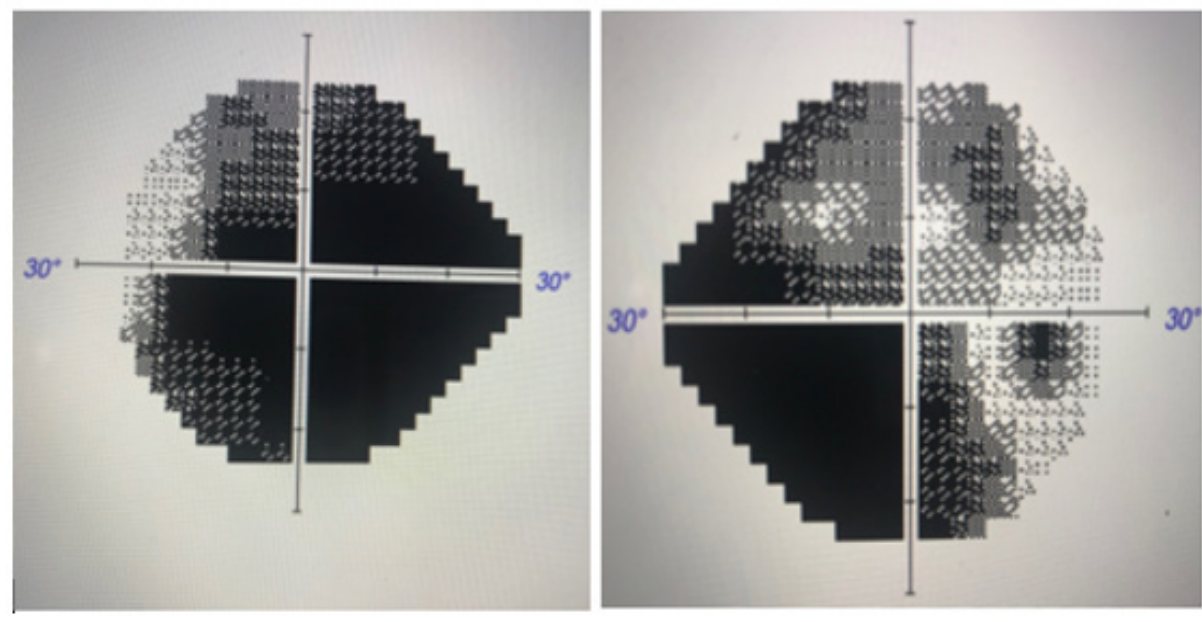

Figure 1 

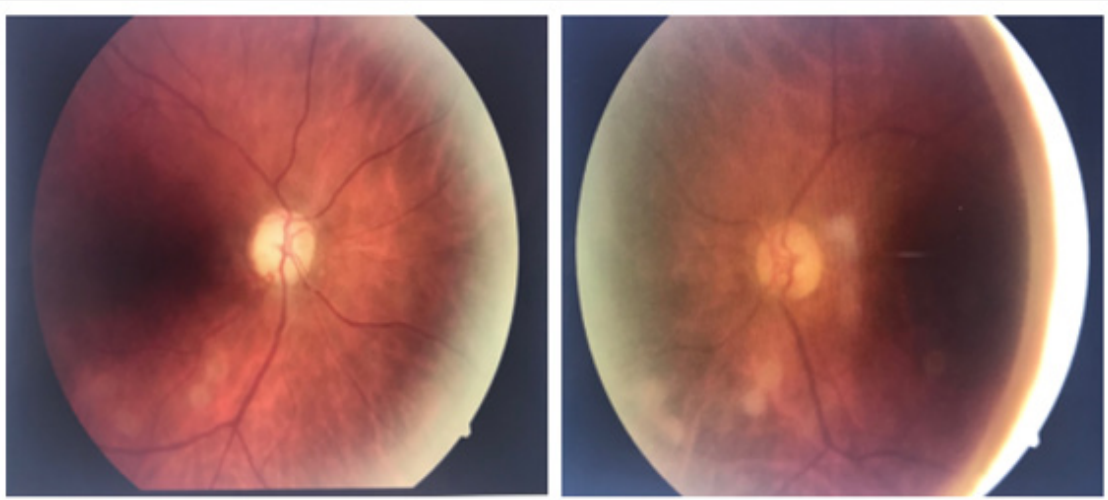

Figure 2

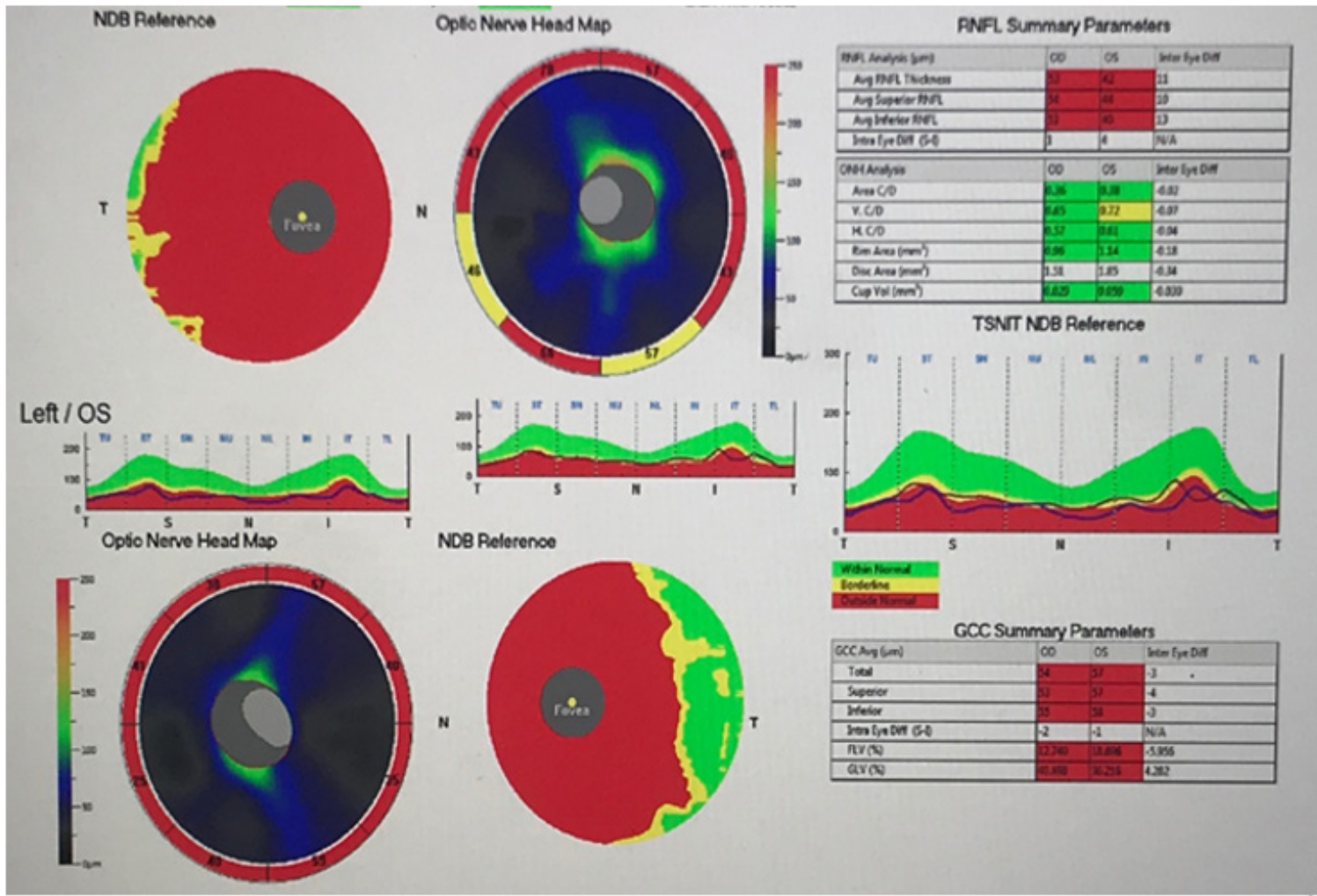

Figure 3

MRI brain and orbit did not reveal any evidence of acute hemorrhage, infarction or other intracranial abnormality. Blood work was within normal limits. We explained about disc at risk and how high or very low blood pressure can cause NAION. The patient has been on Sildenafil (Viagra) when vision loss in second eye happened. There are multiple reports of NAION with using this medication. The patient was highly advised to avoid Sildenafil (Viagra).

\section{Discussion}

Non Arteritic anterior ischemic optic neuropathy (NAION) constitutes $95 \%$ of all anterior ischemic optic neuropathy (AION) and is the most common cause of acute optic neuropathy in people over the age of 50. Approximately 1500 to 6000 new cases per year in the United States are diagnosed with NAION [1]. It is an acute or subacute optic neuropathy which caused by small vessel infarction of the anterior optic nerve. Symptoms include acute, unilateral, usually painless visual loss. Visual acuity (central and peripheral) and color vision are affected. The appearance of the optic disc in the contralateral eye is almost always "disc at risk", which means that there is a crowded optic disc with a small or absent physiologic cup $[2,3]$. The lifelong prevalence of involvement of fellow eye in NAION is about $30 \%$ with incidence rate of $15 \%$ within the first 5 years [4]. In our patient, NAION in the first affected eye was assumed to be related to hyper coagulopathy state, since the patient had a history of pulmonary emboli and he was given blood thinner. Despite of being on Rivaroxaban (Xeralto) the patient developed NAION in the fellow eye. The episode of vision loss happened the day after he used this medication. There are more than 35 million people using Sildenafil (Viagra) since its introduction in 1998 which is 
used to treat erectile dysfunction in men. Several studies and cases were reported in patients who were diagnosed with NAION with the history of taking this medication [5-7]. We are proposing public awareness and patient's education about risk associated with taking Sildenafil (Viagra).

\section{Acknowledgment}

None.

\section{Conflicts of Interest}

No conflict of interest.

\section{References}

1. Atkins EJ, Bruce BB, Newman NJ, Biousse V (2010) Treatment of Nonarteritic Anterior Ischemic Optic Neuropathy. Surv Ophthalmol 55(1): 47-63.
2. Hattenhauer MG, Leavitt JA, Hodge DO, Grill R, Gray DT (1997) Incidence of nonarteritic anterior ischemic optic neuropathy. Am J Ophthalmol 123(1): 103-107.

3. Hayreh SS (2008) Ischemic optic neuropathy. Prog Retin Eye Res 27(6).

4. Mak E. Fellow Eye Involvement in NAION: "Doctor, will I ever be in the clear?". American Academy of Optometry, pp. 1-5.

5. Galvez-Ruiz A and Arishi N (2013) Sequential, non-arteritic anterior ischemic optic neuropathy in patients taking sildenafil: a report of ten cases. Saudi J Ophthalmol 27(4): 241-246.

6. Tarantini A, Faraoni A, Menchini F, Lanzetta P (2012) Bilateral Simultaneous Nonarteritic Anterior Ischemic Optic Neuropathy after Ingestion of Sildenafil for Erectile Dysfunction. Case Rep Med 2012: 747658.

7. Moschos MM and Margetis I (2011) Bilateral simultaneous anterior ischemic optic neuropathy associated with sildenafil. Case Rep Ophthalmol 2(2): 262-265. 